\title{
Stem Cells Therapy in Multiple Sclerosis - A New Hope for Progressive Forms
}

\author{
Ayache $\mathrm{SS}^{1,2,3}$, Chalah $\mathrm{MA}^{1,2}$
}

Multiple sclerosis (MS) is an autoimmune disease of the central nervous system and represents a major cause of disability in young adults. Nowadays, the dichotomy between demyelination and neurodegeneration has been challenged, and both processes are believed to occur independently early in the disease process. 'Relapsing-remitting' MS is the most common subtype which generally shifts to a 'secondary progressive' form; MS progression is usually accompanied by a worsening of the motor, cognitive and emotional symptoms, as well as an increase in the disability level. Primary progressive MS represents a third subtype with severe disability scores, poor prognosis, and usually symptomatic management. In this perspective, an ideal therapy should have immunomodulatory, neuroprotective, regenerative and remyelinating potentials. Here, we discuss the promising abilities of stem cells therapies in patients with MS. The available data are tackled aiming to overcome the previously faced limitations and pave the way for larger scale randomized and controlled studies.

Key Words: Multiple sclerosis, stem cells, progressive multiple sclerosis, therapy

\section{Introduction}

Multiple sclerosis (MS) is an autoimmune disease of the central nervous system $(\mathrm{CNS})^{[1]}$ that manifests as three subtypes, the most common being the 'relapsing-remitting' (RR) which generally shifts to a 'secondary progressive' form (SP). A third type is the 'primary progressive' (PP) MS, characterized by a poor prognosis and usually managed with symptomatic treatments ${ }^{[2]}$. Throughout the disease progression, MS patients can experience a worsening of the motor, cognitive and emotional symptoms, as well as an increase in the disability level. Currently, there is a growing interest toward finding a reparative therapy capable of stopping the disease evolution and reversing the subsequent damage. In other words, a therapy with immunomodulatory, neuroprotective, neuroregenerative and remyelinating effects would be of great help.

In this perspective, stem cells therapies have been evaluated in MS and its animal model, the experimental autoimmune encephalomyelitis (EAE); the available publications include hematopoietic stem cells (HSCs), mesenchymal stem cells (MSCs) and neural stem cells, among others.

\section{Stem cells studies}

To start, HSCs exist in the bone marrow (BM), are able to completely restore all blood-cell lineages after BM ablation in vivo, and by doing so might improve MS patients ${ }^{[3]}$. The rationale behind such a therapy relies on the idea of restoring the aberrant immune system in MS by destroying the autoreactive T-cells and replacing them with non-autoreactive ones. The pioneering preliminary clinical studies using autologous HSCs in MS patients have adapted an open label and uncontrolled design and documented some improvement or stabilization of the clinical and imaging data ${ }^{[4-6]}$. However, they reported some degree of transplantrelated mortality ${ }^{[4,5]}$. In a recent, multicenter, phase II, randomized trial, $21 \mathrm{RR}$ or SP MS patients received either HSCs or mitoxantrone ${ }^{[7]}$. A significant improvement was found in the HSCs group compared to their mitoxantrone-treated counterparts, as evidenced by improvement in the annual relapse rate and MRI parameters. Keeping in mind that a full eradication of all the hematopoietic cells (myeloablation) is faced with numerous side effects, applying a selective eradication of self-reactive T cells (nonmyeloablation) might be sufficient to halt the progression of the disease. This idea was supported by one study involving 4 RR, 4 PP and 33 SP MS patients ${ }^{[8]}$. Here, low intensity HSCs transplantation resulted in a promising clinical outcome with lesser lethality or side effects compared to intermediate intensity HSCs therapy.

However, the immunomodulatory and immunosuppressive abilities of HSCs alone might be unable to improve late-stage progressive MS, where axonal damage is the hallmark behind the neurological deterioration. In this perspective, MSCs might be an appealing tool to overcome these limitations. MSCs are pluripotent nonhematopoietic precursor cells that could be harvested from different sites, mainly the BM (BM-MSCs), adipose tissues, or umbilical cords. In vitro and in vivo, MSCs can differentiate into other lines of mesodermal cells, as well as to non-mesenchymal cell lineages, particularly to neurons ${ }^{[9]}$. EAE studies proposed the MSCs ability to promote neurorehabilitation through various mechanisms such as decreasing the inflammatory cells infiltration into the CNS, inducing $\mathrm{T}$-cell anergy, promoting the proliferation of regulatory $\mathrm{T}$ cells, recruiting local progenitors, among others. They can act either directly by engrafting into the damaged CNS lesions or indirectly by involving paracrine mechanisms and inducing multiple restorative pathways ${ }^{[9]}$. The published clinical studies were phase $\mathrm{I}^{[10-14]}$ or

Author Names in full: Samar S. Ayache ${ }^{1,2,3}$, Moussa A. Chalah ${ }^{1,2}$

${ }^{1}$ EA 4391, Excitabilité Nerveuse et Thérapeutique, Université Paris-Est-Créteil, France, ${ }^{2}$ Service de Physiologie - Explorations Fonctionnelles, Hôpital Henri Mondor, Assistance Publique - Hôpitaux de Paris, France, ${ }^{3}$ Neurology Division, University Medical Center Rizk Hospital, Beirut, Lebanon. 
phase $\mathrm{II}^{[15]}$ trials that administered autologous MSCs to MS patients. Most of them have denied transplant-related major adverse events and further documented some clinical or radiological benefits following the intrathecal (IT) or intravenous (IV) administration of autologous MSCs. However, this should be interpreted with caution admitting their open-label design. To overpass these limitations, a randomized placebo-controlled phase II trial has administered a single IV dose of autologous MSCs or placebo to 9 MS patients ${ }^{[16]}$. The treatment resulted in a trend wise decrease in the cumulative gadolinium enhanced lesions at 6 months and a reduction in their mean number at 12 months. However, it did not differ from placebo in terms of disability progression.

Besides administering a single IV dose of BM-MSCs, the rationale for using multiple doses has been supported by recent studies. In one of them, Lublin and colleagues ran a randomized, placebo-controlled study in $16 \mathrm{MS}$ patients ${ }^{[17]}$. The latter has highlighted the safety profile and the encouraging clinical outcome that resulted from the administration of multiple IV doses of mesenchymal-like cells derived from healthy, full-term human placental tissue. In another study, $\mathrm{Li}$ and colleagues have administered either an anti-inflammatory treatment alone (control group) or in combination with IV human umbilical cord-derived MSCs (hUC-MSCs) three times in a 6-week period for each of the 23 enrolled MS patients ${ }^{[18]}$. The hUC-MSCstreated patients had a significantly lower disability scores and relapses and a shift from Th1 to Th2 immunity compared to the control group.

All these studies confirm the safety profile of MSCs, whereas the discrepancy in their outcomes could have arisen from various points of difference that deserve to be addressed. First, MS patients represent a heterogeneous group with diverse presentations and clinical outcomes. In this context, MSC trials have presented a great variability regarding patients characteristics; for instance, some studies have recruited patients with unspecified active $M S^{[11]}$, while others have enrolled patients with RR MS ${ }^{[16]}$, progressive MS ${ }^{[10,12-15]}$ or both ${ }^{[17]}$.

Second, the route of administration varied among studies; it consisted of $\mathrm{IV}^{[12,15-17]}$ IT $^{[10,13,14]}$, or both routes ${ }^{[11]}$. Keeping in mind that EAE studies with positive outcomes used the intrathecal route ${ }^{[19]}$ and that most of the MS intrathecal trials were tolerated except in one patient who received high dose ${ }^{[13]}$; this route might be superior to the IV one for the following reasons: on the one hand, the controversy regarding the ability of the IV dose to cross the blood-brain barrier might limit its mechanism of action to immunomodulation without regeneration ${ }^{[20]}$. On the other hand, IT local effects are needed in progressive MS where disability is usually associated with spinal cord pathologies. Third, the difference in the number of doses could be an important contributor to the observed variation in responses, as multiple doses were required to induce clinical benefits compared to a single dose in some EAE studies ${ }^{[19]}$. Fourth, the difference in the origin, the preparation and the storage conditions of MSCs can also have an impact on the various studies outcomes.

Besides the classical use of MSCs, mesenchymal stem cell-derived neural progenitors (MSC-NPs) are a subpopulation of MSCs with reduced potential of unwanted mesodermal differentiation which makes them more suitable for CNS transplantation ${ }^{[21]}$. Interestingly, an ongoing phase I clinical trial is currently administering MSC-NPs to patients with progressive MS with a design that takes into consideration the above limitations: Three doses of autologous IT MSC-NPs separated with a three-month interval ${ }^{[21]}$. Its results are highly awaited.

\section{Future perspectives}

The above data altogether support the potential benefits of HSCs and MSCs in patients with progressive MS, and should pave the way for large-scale studies, that compare the outcomes of different variables (origin of stem cells, dose amount and number, route of administration, storage conditions, etc.).

Other stem cells therapies are being investigated, namely the potential role of induced pluripotent stem cells (iPSCs), which can be harvested from almost any somatic cell type ${ }^{[9]}$. Interestingly, iPSCsderived neural precursors cells and oligodendrocyte precursor cells could develop into mature oligodendrocytes and might therefore constitute good candidates for restoring the remyelination process in MS. However, sufficient evidence is still lacking and further studies are needed before drawing any conclusion.

\section{References}

1. Compston A, Coles A. Multiple sclerosis. Lancet. 2008; 372(9648):1502-17.

2. Rice CM, Cottrell D, Wilkins A, Scolding NJ. Primary progressive multiple sclerosis: progress and challenges. J. Neurol. Neurosurg. Psychiatry. 2013; 84(10):1100-6.

3. Holloman JP, Ho CC, Hukki A, Huntley JL, Gallicano GI. The development of hematopoietic and mesenchymal stem cell transplantation as an effective treatment for multiple sclerosis. Am J Stem Cells. 2013; 2(2):95-107.

4. Saccardi R, Kozak T, Bocelli-Tyndall C, Fassas A, Kazis A, Havrdova E, Carreras E, Saiz A, Löwenberg B, te Boekhorst PA, Gualandio F, Openshaw H, Longo G, Pagliai F, Massacesi L, Deconink E, Ouyang J, Nagore FJ, Besalduch J, Lisukov IA, Bonini A, Merelli E, Slavino S, Gratwohl A, Passweg J, Tyndall A, Steck AJ, Andolina M, Capobianco M, Martin JL, Lugaresi A, Meucci G, Sáez RA, Clark RE, Fernandez MN, Fouillard L, Herstenstein B, Koza V, Cocco E, Baurmann H, Mancardi GL; Autoimmune Diseases Working Party of EBMT. Autologous stem cell transplantation for progressive multiple sclerosis: update of the European Group for Blood and Marrow Transplantation autoimmune diseases working party database. Mult Scler. 2006; 12(6):814-23

5. Mancardi GL, Sormani MP, Di Gioia M, Vuolo L, Gualandi F, Amato MP, Capello E, Currò D, Uccelli A, Bertolotto A, Gasperini C, Lugaresi A, Merelli E, Meucci G, Motti L, Tola MR, Scarpini E, Repice AM, Massacesi L, Saccardi R; Italian BMT Study Group. Autologous haematopoietic stem cell transplantation with an intermediate intensity conditioning regimen in multiple sclerosis: the Italian multi-centre experience. Mult Scler. 2012; 18(6):835-42.

6. Burt RK, Balabanov R, Han X, Sharrack B, Morgan A, Quigley K, Yaung K, Helenowski IB, Jovanovic B, Spahovic D, Arnautovic I, Lee DC, Benefield BC, Futterer S, Oliveira MC, Burman J. Association of nonmyeloablative hematopoietic stem cell transplantation with neurological disability in patients with relapsing-remitting multiple sclerosis. JAMA. 2015; 313(3):27584.

7. Mancardi GL, Sormani MP, Gualandi F, Saiz A, Carreras E, Merelli E, Donelli A, Lugaresi A, Di Bartolomeo P, Rottoli MR, Rambaldi A, Amato MP, Massacesi L, Di Gioia M, Vuolo L, Currò D, Roccatagliata L, Filippi M, Aguglia U, Iacopino P, Farge D, Saccardi R; ASTIMS Haemato-Neurological Collaborative Group, On behalf of the Autoimmune Disease Working Party (ADWP) of the European Group for Blood and Marrow Transplantation (EBMT); ASTIMS Haemato-Neurological Collaborative Group On behalf of the Autoimmune Disease Working Party ADWP of the European Group for Blood and Marrow Transplantation EBMT. Autologous hematopoietic stem cell transplantation in multiple sclerosis: a phase II trial. Neurology. 2015; 84(10):981-8. 
8. Hamerschlak N, Rodrigues M, Moraes DA, Oliveira MC, Stracieri AB, Pieroni F, Barros GM, Madeira MI, Simões BP, Barreira AA, Brum DG, Ribeiro AA, Kutner JM, Tylberi CP, Porto PP, Santana CL, Neto JZ, Barros JC, Paes AT, Burt RK, Oliveira EA, Mastropietro AP, Santos AC, Voltarelli JC. Brazilian experience with two conditioning regimens in patients with multiple sclerosis: BEAM/horse ATG and CY/rabbit ATG. Bone Marrow Transplant. 2010; 45(2):239-48.

9. Xiao J, Yang R, Biswas S, Qin X, Zhang M, Deng W. Mesenchymal stem cells and induced pluripotent stem cells as therapies for multiple sclerosis. Int J Mol Sci. 2015; 16(5):9283302.

10. Mohyeddin Bonab M, Yazdanbakhsh S, Lotfi J, Alimoghaddom K, Talebian F, Hooshmand F, Ghavamzadeh A, Nikbin B. Does mesenchymal stem cell therapy help multiple sclerosis patients? Report of a pilot study. Iran J Immunol. 2007; 4(1):50-7.

11. Karussis D, Karageorgiou C, Vaknin-Dembinsky A, GowdaKurkalli B, Gomori JM, Kassis I, Bulte JW, Petrou P, Ben-Hur T, Abramsky O, Slavin S. Safety and immunological effects of mesenchymal stem cell transplantation in patients with multiple sclerosis and amyotrophic lateral sclerosis. Arch Neurol. 2010; 67(1):1187-1194.

12. Rice CM, Mallam EA, Whone AL, Walsh P, Brooks DJ, Kane N, Butler SR, Marks DI, Scolding NJ. Safety and feasibility of autologous bone marrow cellular therapy in relapsing-progressive multiple sclerosis. Clin Pharmacol Ther. 2010; 87(6): 679-685.

13. Yamout B, Hourani R, Salti H, Barada W, El-Hajj T, Al-Kutoubi A, Herlopian A, Baz EK, Mahfouz R, Khalil-Hamdan R, Kreidieh NM, El-Sabban M, Bazarbachi A. Bone marrow mesenchymal stem cell transplantation in patients with multiple sclerosis: a pilot study. J Neuroimmunol. 2010; 227(1-2): 185-189.

14. Bonab MM, Sahraian MA, Aghsaie A, Karvigh SA, Hosseinian SM, Nikbin B, Lotfi J, Khorramnia S, Motamed MR, Togha M, Harirchian MH, Moghadam NB, Alikhani K, Yadegari S, Jafarian S, Gheini MR. Autologous mesenchymal stem cell therapy in progressive multiple sclerosis: an open label study. Curr Stem Cell Res Ther. 2012; 7(6): 407-414.
15. Connick P, Kolappan M, Crawley C, Webber DJ, Patani R, Michell AW, Du MQ, Luan SL, Altmann DR, Thompson AJ, Compston A, Scott MA, Miller DH, Chandran S. Autologous mesenchymal stem cells for the treatment of secondary progressive multiple sclerosis: an open-label phase 2 a proof ofconcept study. Lancet Neurol. 2012; 11(2): 150-156.

16. Llufriu S, Sepúlveda M, Blanco Y, Marín P, Moreno B, Berenguer J, Gabilondo I, Martínez-Heras E, Sola-Valls N, Arnaiz JA, Andreu EJ, Fernández B, Bullich S, Sánchez-Dalmau B, Graus F, Villoslada P, Saiz A. Randomized placebo-controlled phase II trial of autologous mesenchymal stem cells in multiple sclerosis. PLoS One. 2014; 9(12):e113936.

17. Lublin FD, Bowen JD, Huddlestone J, Kremenchutzky M, Carpenter A, Corboy JR, Freedman MS, Krupp L, Paulo C, Hariri RJ, Fischkoff SA. Human placenta-derived cells (PDA-001) for the treatment of adults with multiple sclerosis: a randomized, placebo-controlled, multiple-dose study. Mult Scler Relat Disord. 2014; 3(6):696-704.

18. Li JF, Zhang DJ, Geng T, Chen L, Huang H, Yin HL, Zhang YZ, Lou JY, Cao B, Wang YL. The potential of human umbilical cordderived mesenchymal stem cells as a novel cellular therapy for multiple sclerosis. Cell Transplant. 2014; 2014;23 Suppl 1:S11322.

19. Harris VK, Yan QJ, Vyshkina T, Sahabi S, Liu X, Sadiq SA. Clinical and pathological effects of intrathecal injection of mesenchymal stem cell-derived neural progenitors in an experimental model of multiple sclerosis. J Neurol Sci. 2012; 313(1-2):167-77.

20. Gordon D, Pavlovska G, Uney JB, Wraith DC, Scolding NJ. Human mesenchymal stem cells infiltrate the spinal cord, reduce demyelination, and localize to white matter lesions in experimental autoimmune encephalomyelitis. J. Neuropathol. Exp. Neurol. 2010; 69(11):1087-1095.

21. Harris VK, Vyshkina $\mathrm{T}$, Chirls $\mathrm{S}$, Sadiq SA. Intrathecal administration of mesenchymal stem cell-neural progenitors in multiple sclerosis: an interim analysis of a phase I clinical trial. Abstract. ACTRIMS. 2014.

\footnotetext{
Abbreviations

MS : Multiple Sclerosis

CNS : Central Nervous System

RR : Relapsing-Remitting

SP : Secondary Progressive

PP : Primary Progressive

EAE : Experimental Autoimmune Encephalomyelitis

HSCs : Hematopoietic Stem Cells

MSCs : Mesenchymal Stem Cells

BM : Bone Marrow

BM-MSCs : Bone Marrow-Derived Mesenchymal Stem Cells

IV : Intravenous

IT : Intrathecal

hUC-MSCs: Human Umbilical Cord-Derived Mesenchymal Stem Cells

MSC-NPs : Mesenchymal Stem Cell-Derived Neural Progenitors

iPSCs : : Induced Pluripotent Stem Cells
}

\section{Potential Conflicts of Interests}

None

\section{Corresponding Author}

Samar S. Ayache, Service de Physiologie - Explorations Fonctionnelles, Hôpital Henri Mondor, Assistance Publique - Hôpitaux de Paris, 94010, Créteil, France. Email: samarayache@gmail.com 